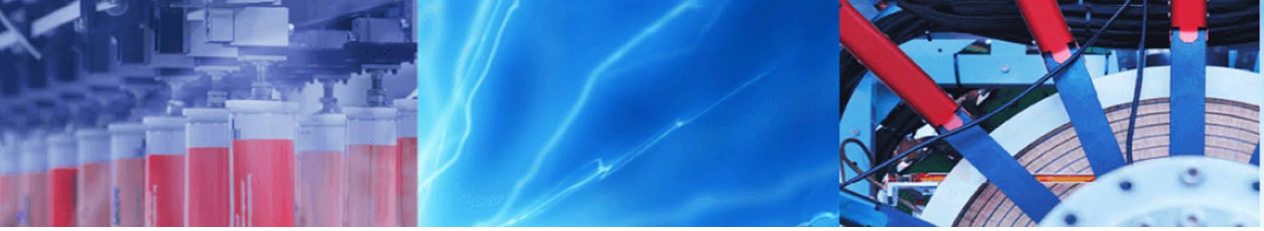

Research Article

\title{
Garcinia cambogia extract alters anxiety, sociability, and dopamine turnover in male Swiss albino mice
}

\author{
Michael K. Ibrahim ${ }^{1} \cdot$ Aboelsaad Marina $^{2} \cdot$ Fatma Tony $^{2} \cdot$ Moustafa Sayed $^{2,3}$
}

Received: 18 October 2021 / Accepted: 29 November 2021

Published online: 18 December 2021

(c) The Author(s) 2021 OPEN

\begin{abstract}
Obesity is a global concern, closely allied with somatic and psychosomatic disorders. Herbal drugs are available in modern medicine to treat obesity. Garcinia camobogia being used by so many people trying to lose weight produces various systemic side effects. The study was conducted to assess its effect on anxiety, sociability, and dopamine turnover in male mice. Twenty-one male Swiss albino mice of either were divided into three groups with seven mice in each group. Control group was given distilled water $(0.5 \mathrm{ml}$ p.o.) and the other two groups received Garcinia cambogia extract at two different doses, a low and a higher dose $(100 \mathrm{mg} / \mathrm{kg}$ and $500 \mathrm{mg} / \mathrm{kg}$. p.o.) Each animal received a single oral dose daily, which was administered using an oral gavage for fourteen consecutive days. Effect of test drugs on anxiety was evaluated using open field test. Sociability and social novelty were evaluated using three chambers test. Results (mean \pm SD) were analyzed using one-way ANOVA test followed by Tukey's test. Garcinia cambogia extract significantly increased the time spent in the corners in the open field test, significantly reduced sociability and social novelty in the three-chamber test, significantly reduced dopamine turnover in the brain with a significant decrease in dopamine metabolite homovanillic acid (HVA) and increased $D_{2}$ receptor expression in ventral tegmental area. Garcinia cambogia extract have significant anxiogenic effect along with reduced sociability and social novelty in male mice. Moreover, these effects could be related to the altered dopamine turnover and $D_{2}$ receptor expression in mice brain.
\end{abstract}

\section{Article Highlights}

- Chronic used of alcoholic extract of Garcinia campbogia lead to a significant increase in anxiety that was manifested by the reduced time in the center zone and increased immobility in the open field test.

- Garcinia camobogia chronic administration has a profound impact on sociability and social novelty with a significant decrease in both behavioral patterns compared to the control group.

- These effects could be attributed to the noticed change in the dopamine turnover in the brain with a significant decrease in dopamine metabolite (HVA) and an upward expression of $D 2$ receptors in return.

Keywords Anxiety · Sociability · Social novelty · Dopamine D 2 receptor $\cdot$ Homovanillic acid $\cdot$ Nucleus accumbens . Ventral tegmental area - Garcinia cambogia

$\triangle$ Moustafa Sayed, helmy.mostafa@bue.edu.eg| ${ }^{1}$ Department of Developmental Pharmacology, Egyptian Drug Authority (EDA), Giza, Egypt. ${ }^{2}$ Clinical Pharmacy Practice Department, Faculty of Pharmacy, The British University in Egypt (BUE), P.O. Box 43, El-Sherouk City, Cairo, Egypt. ${ }^{3}$ Center of Drug Research and Development (CDRD), Faculty of Pharmacy, The British University in Egypt (BUE), El-Sherouk City, Cairo, Egypt. 


\section{Introduction}

Obesity continues to plague the world at an alarming rate, being overweight or obese causes significant health and social distress. According to the WHO, worldwide obesity has increased three-folds since 1975 [1]. Moreover, in 2016, 1.9 billion adults have been found to be overweight, 650 million of these are considered obese [2]. The WHO defines overweight as having a body mass index (BMI) greater than or equal to $25 \mathrm{~kg} / \mathrm{m}^{2}$ and obesity as a BMI greater than or equal to $30 \mathrm{~kg} / \mathrm{m}^{2}$ [2]. A raised $\mathrm{BMl}$ is a key factor for occurrence of noncommunicable disease such as atherosclerosis, cardiovascular disease, diabetes and even some cancers leading to premature death [3]. There are some drugs in the market that aim to prevent or ameliorate obesity, but their efficacy and side effects needs further consideration [4].

Furthermore, evidence is starting to emerge on the consumption of plant-based and herbal products as an effective approach for treatment of disease. We found that several studies have shed light on a small fruit, Garcinia cambogia also known as; Garcinia gummi-gutta, which is widely advertised as a supplement for weight loss [5], Garcinia cambogia is a small fruit native to southeastern Asia and has been commonly used as a food bulking agent, flavoring agent, and as a food preservative $[5,6]$. The plant extract exhibited biological activity such as anti-obesity, strong hypolipidemic activity [7], as well as anti-inflammatory and antioxidant activity [5] Click or tap here to enter text..

Hydroxycitric acid (HCA), the major organic acid occurring in the fruit and its main active constituent $[5,8]$, HCA has shown its anti-obesity effect by multiple mechanisms where it reduces food intake as it regulates serotonin levels which controls satiety by inducing an appetite suppressant effect [9]. Moreover, it reduces weight gain by the inhibition of the enzyme adenosine triphosphate citrate lyase which catalyzes the extra mitochondrial cleavage of citrate into oxaloacetate and Acetyl-CoA, where Acetyl-CoA is a building block of fatty acid synthesis, hence inhibition of fatty acid synthesis; Additionally, HCA decreased de novo lipogenesis and increased fat oxidation [5], However a randomized control trial showed dissimilar results and demonstrated that the administration of Garcinia cambogia extract failed to exhibit significant weight reduction or fat loss when compared to the placebo [10].

On the other hand, the serotonergic effects of HCA are alarming and when combined with selective serotonin reuptake inhibitor it can contribute to serotonin syndrome. For instance, several cases of mania, hypomania and/or psychosis have been reported after the consumption of Garcenia cambogia extract or supplements [11-15]. Moreover, Garcinol, which is a compound isolated from the bark of G. cambogia [5] has shown anti-inflammatory as well as antioxidant activity by suppressing the expression of inducible nitric oxide (iNOS) synthase involved in the immune response [16]. Furthermore, Garcinol increases the bioavailability of Dopamine (DA) and L-Dopa by inhibition of Catechol-OMethyltransferase enzyme (COMT) where COMT catabolizes DA and L-Dopa into 3-methoxytyramine (3-MT) and 3-O-methyldopa (3-OMD) respectively hence decreasing levels of dopamine and L-dopa [17], which raises a question regarding the effect of Garcinia extract on the dopaminergic pathways of the brain. To further illustrate, dopamine is a neurotransmitter in the central nervous system which contributes to the coordination of movement, learning, memory, and reward seeking behavior [18].

There are four major dopaminergic pathways in the brain. Firstly, the mesolimbic pathway where dopaminergic neurons arise from the ventral tegmental area (VTA) and projects into the nucleus accumbens (NAC) [18], this pathway is responsible for the positive symptoms of schizophrenia as hallucinations and delusions due to the increase of dopamine levels [19]. Secondly, the mesocortical pathway which arises from the ventral tegmental area (VTA) and projects to the cortex, this is responsible for the negative symptoms of schizophrenia as social withdrawal and emotional blunting due to decrease of dopamine levels $[18,19]$. Where these two pathways overlap at the VTA and hence are called the mesocorticolimbic-dopamine system, where it is proposed that they regulate emotionrelated behavior $[18,20]$. Thirdly, the nigrostriatal pathway where dopaminergic neurons start in the substantia nigra (SN) and projects to the striatum, this pathway is responsible for the coordination of movement, where Parkinson's disease extrapyramidal symptoms (ex. tremor, bradykinesia, loss of postural control and rigidity) are due to decreased dopamine levels in this pathway $[17,18]$. And fourthly, the tuberoinfundibular pathway arising from the hypothalamus to the pituitary gland. In this study we aimed at assessing the potential of Garcinia to alter dopaminergic pathways (substania nigra, nucleus accumbens and frontal cortex) and reward circuits in the brain and its effects on locomotor activity and sociability in male mice.

\section{Materials and methods}

Animals Male Swiss albino mice (25-30 g), obtained from the animal facility of the British University in Egypt (BUE), were used. Animals were kept undisturbed for accommodation (4 animals per cage, 12/12 light-dark cycle, 
$24 \pm 2{ }^{\circ} \mathrm{C}$ ambient temperature, $50-60 \%$ humidity and food and water ad libitum).

Drug Garcenia Combagia extract (GC) was a generous gift from dBK pharma (S.A.E.). The drug was freshly prepared daily. The extract was dissolved in double-distilled water and was orally administrated at two dose levels 100 and $500 \mathrm{mg} / \mathrm{Kg}$.

Experimental design 21 animals (7/group) were randomly assigned into either control (distilled water), GC low dose $(100 \mathrm{mg} / \mathrm{Kg})$ or $\mathrm{GC}$ high dose $(500 \mathrm{mg} / \mathrm{Kg})$. Each animal received a single daily oral dose using an oral gavage for fourteen consecutive days.

Behavioral assessment On the 14th Day, 2-3 h after the last dose, animals were transferred in their home cages to a sound-attenuated test room one hour before the experimental procedure. Mice were introduced to the open field test followed by the three-chamber social interaction procedure on the following day. Test sessions were videotaped using a top-mounted camera and were analyzed by a trained observer, blinded to groups and treatments using a validated software (Any-maze ${ }^{\mathrm{TM}}$, Stoelting Co., Chicago, USA). The animals were then sacrificed with minimal disturbance using large surgical scissors and the brain was harvested and rapidly dissected for ventral tegmental (VT), nucleus accumbens (NA) and frontal cortex (FC). Dissected tissues were snap-frozen using liquid nitrogen and stored at $-80^{\circ} \mathrm{C}$ for later procedures.

Open field test The test was performed according to Paylor et al. [21]. In brief, the open field (OF) is a black matte plexiglass box $(\mathrm{l} \times \mathrm{w} \times \mathrm{h}=40 \times 40 \times 30 \mathrm{~cm})$ [21]. Each mouse was allowed to explore the arena for $10 \mathrm{~min}$ before being returned to its home cage. The open field apparatus was cleaned with $70 \%$ alcohol between tests. Videos were analyzed for (1) total time traveled in the central zone (2) the total number of line crossings (3) rearing frequency [22-25].

Three chamber social interaction test The test is utilized for quantitative assessment of sociability and preference for social novelty. The apparatus comprised a rectangular box $(\mathrm{I} \times \mathrm{w} \times \mathrm{h}=60 \times 40 \times 22 \mathrm{~cm})$ separated into three equal chambers by means of a movable separating partitions with small square openings $(6 \times 4 \mathrm{~cm})$ allowing free movement between chambers. A naïve male mouse that had no prior contact with the subject mouse was placed in one of the side chambers (stranger 1). The placement of stranger 1 in the left or right-side chambers was systematically alternated between trials. The stranger mouse was enclosed in a cylindrical wire cage $(\mathrm{d} \times \mathrm{h}=9 \times 11 \mathrm{~cm}$, wires are $0.5 \mathrm{~cm}$ apart) that allowed contact between the bars but prevented fighting. The subject mouse was allowed to explore the entire arena for 10-min, the time spent in each chamber and the time spent within a $5-\mathrm{cm}$ distance of the wire cage were measured. At the end of the first $10 \mathrm{~min}$, a second unfamiliar mouse was placed in the other empty.

Neurochemical assessment Dopamine content, HVA concentration and $D 2$ receptor were measured in the aforementioned brain regions using Sandwich ELISA technique as previously described [26]. After behavioral tests, mice were decapitated. The aforementioned brain regions were rapidly obtained and kept stored at $-80^{\circ} \mathrm{C}$ for further analysis. The brain regions were homogenized in a lysis buffer (containing $137 \mathrm{mM} \mathrm{NaCl}, 20 \mathrm{mM}$ Tris $(\mathrm{pH}$ 8.0), $1 \%$ NP40, $10 \%$ glycerol, $1 \mathrm{mM} \mathrm{PMSF}, 10 \mathrm{mg} / \mathrm{mL}$ aprotinin, $1 \mathrm{mg} / \mathrm{ml}$ leupeptin, and $0.5 \mathrm{mM}$ sodium vanadate) by using a tissue homogenizer and then incubated at $4{ }^{\circ} \mathrm{C}$ for $1 \mathrm{~min}$ while shaking. Homogenates were centrifuged, and supernatants were collected. The total concentrations of Dopamine, HVA and D2 receptor were measured by an ELISA kit. The kit was obtained from BT lab- China (Cat no. for DA: E0667Mo, HVA: E1482Ra and D2; E0971Mo). All steps of the assay were performed according to the supplier's user instructions.

\subsection{Statistical analysis}

Data were expressed as mean \pm SD. Multiple comparisons among groups were analyzed using one-way analysis of variance (ANOVA) followed by Tukey test as a post-hoc test. The probability level less than 0.05 was considered to indicate statistical significance. All Statistical procedures were performed using IBM SPSS version 17 computer package, USA. Graphs were sketched using GraphPad Prism version 8 software (GraphPad Software Inc., USA).

\section{Results}

\subsection{Effects of Garcinia cambogia extract on locomotor activity}

Regarding locomotive pattern in OF, both doses of Garcinia (100 mg and $500 \mathrm{mg} / \mathrm{kg}$ ) significantly decreased time spent in the center with a corresponding increase in the time spent in the corners when compared to the control group $\left(F_{(2,18)}=39.14\right.$ and 29.12 respectively) (Fig. $\left.1 C, D\right)$. In addition, a dose dependent increase in the immobility time, although statistically significant in the high dose group only, was observed compared to the control group $\left(F_{(2,18)}=4.11\right)$ (Fig. 1E). Moreover, both doses of Garcinia decreased the total distance and the average speed of treated animals in OF. However, such increase was statistically insignificant in comparison to the control group (Fig. 1A, B). 
Fig. 1 Effect of low and high dose of Garcinia extract on total distance $(\mathbf{A})$, average speed (B), time in the center (C), time in the corners (D) and total immobility (E) expressed by the treated mice in the open field test (OF). The locomotion pattern is illustrated $(\mathbf{F})$. Data are plotted as mean \pm SD $(n=7)$. *Significantly different from control
A

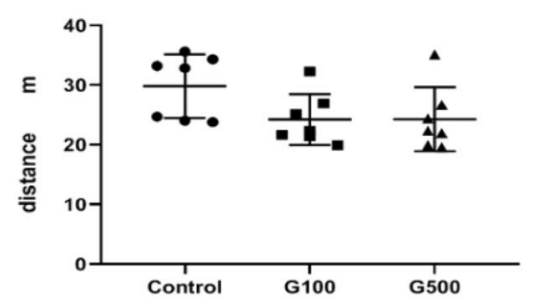

C

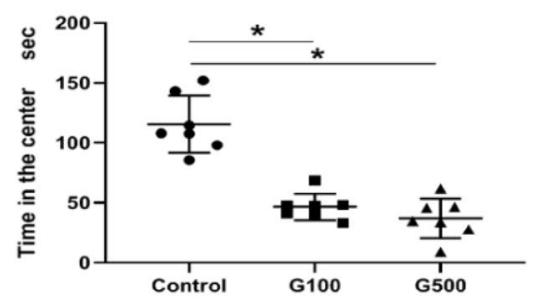

B

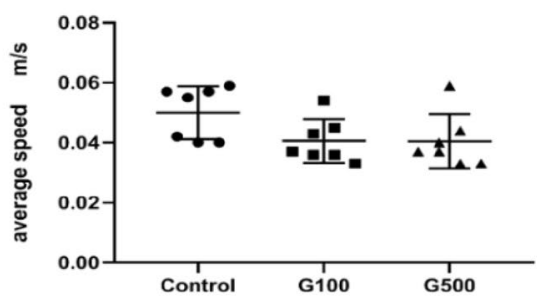

D

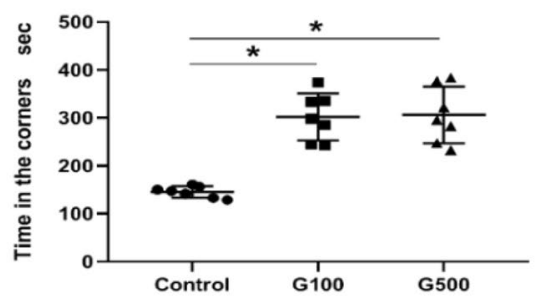

E

$\mathbf{F}$

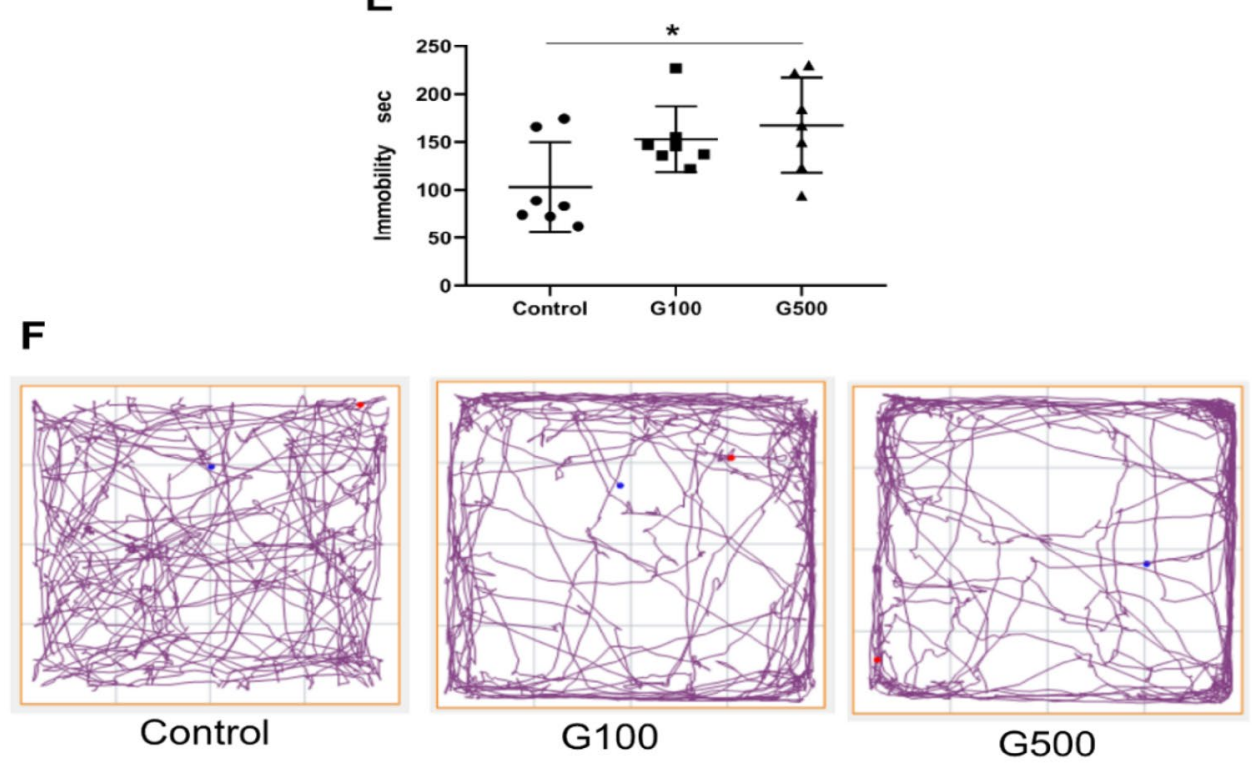

\subsection{Effects of Garcinia cambogia extract on sociability and social novelty}

In the three-chamber social interaction test, Garcinia extract, at both dose levels examined, significantly altered sociability and social novelty compared to the control group. Both doses (100 mg and $500 \mathrm{mg} / \mathrm{Kg}$ ) showed significant decrease in time of contact with living animal compared with empty cage was observed when compared to the control group $\left(F_{(92,18)}=7.54\right.$ and 13.84, respectively) (Fig. 2A). A similar impact on social novelty was recognized, as animals of both treatment groups spent significantly longer time with the familiar animal and shorter time with the novel one as compared with control $\left(\mathrm{F}_{(2,18)}=6.3\right.$ and 24.52 respectively) (Fig. $\left.2 \mathrm{~B}\right)$.

\subsection{Effects of Garcinia cambogia on the expression levels of Dopamine, HVA and $D_{2}$ receptor in different brain areas}

The $500 \mathrm{mg} / \mathrm{Kg}$ treatment with Garcinia cambogia showed a significant increase in the dopamine content in both FC and NAc regions only when compared with the control group $\left(\mathrm{F}_{(2,12)}=5.21\right)$. In addition, low dose treatment $(100 \mathrm{mg} / \mathrm{Kg}$ ) increased dopamine content in only NAC and VTA regions when compared to the control group 

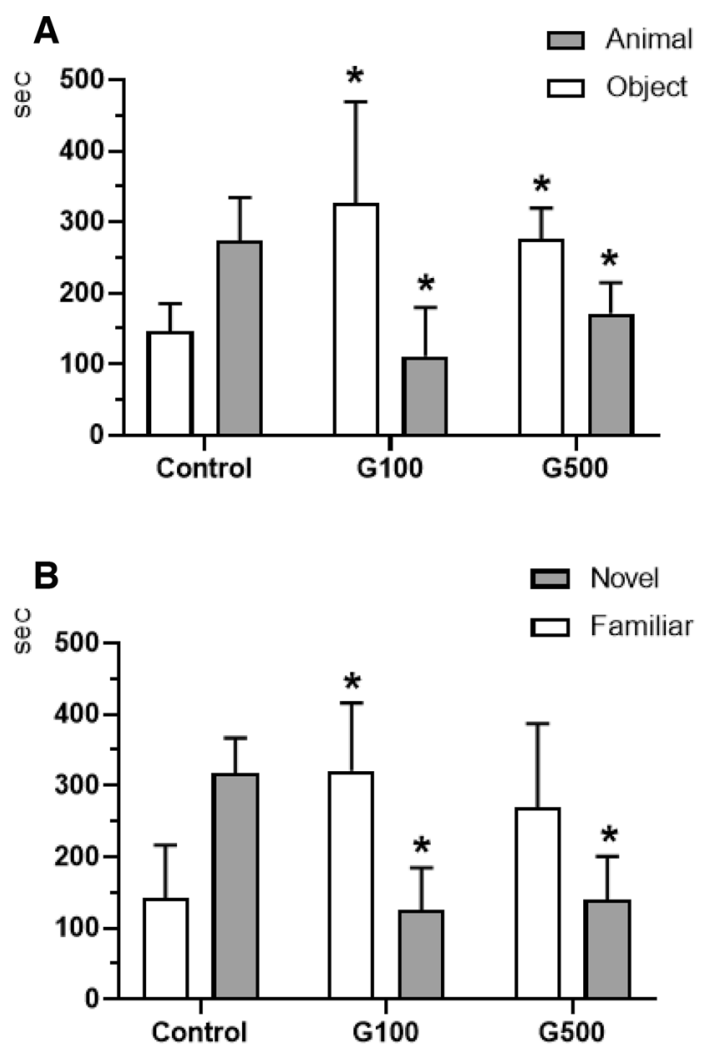

Fig. 2 Effect of low and high dose of Garcinia on sociability (A) and social novelty (B) in the three chambers social interaction test. Data are plotted as mean $\pm S D(n=7)$. *Significantly different from control

$\left(\mathrm{F}_{2,12}=6.11\right)$ (Fig. 3A). With respect to HVA content, the $100 \mathrm{mg} / \mathrm{Kg}$ treatment resulted in a significant reduction of the HVA content in both NAC and VTA regions only when compared to the control group $\left(\mathrm{F}_{(2.12)}=28.49\right.$ and 46.08 respectively) (Fig. 2B). However, the higher dose of Garcinia didn't show a significant change compared to the control group. Finally, only the high dose treatment of Garcinia showed a significant increase in the D2 receptor content in the VTA region only when compared to the control group $\left(\mathrm{F}_{(2,12)}=6.64\right)$ (Fig. 3C).

\section{Discussion}

Anxiety and depression are the most prevelant forms of neuropsychiatric disorders. Depression is a severe yet common condition with significant recurrence and mortality rates [27]. Anxiety is defined as an apathetic emotional state characterised by excessive fear and worry in relation to the nature of the threat [28]. Long-term administration of Garcinia cambogia extract (GC) for 2 weeks consecutively showed an increased level of anxiety and depression in treated mice. GC extract enhanced the time spent
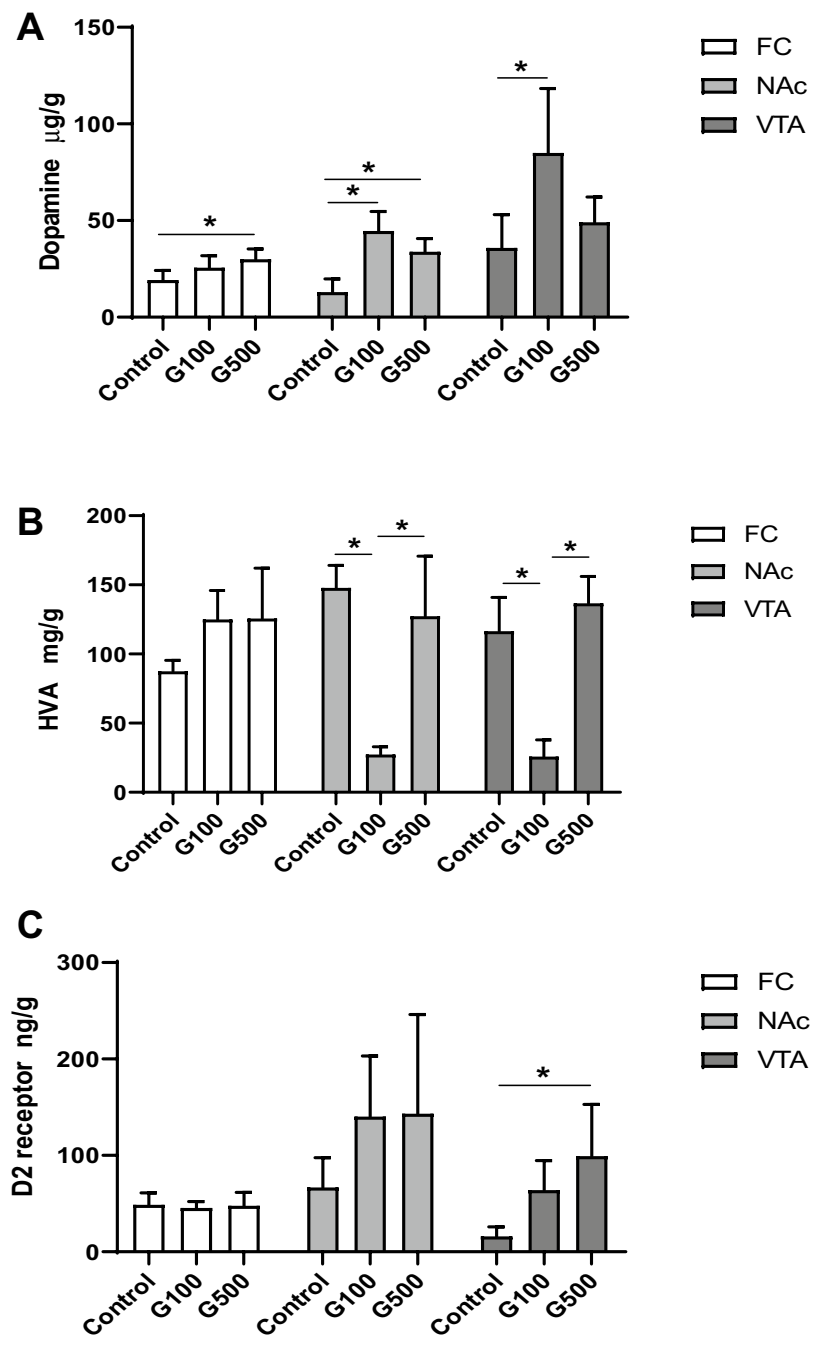

Fig. 3 Effect of low and high dose of Garcinia on Dopamine (A), HVA (B) and $D_{2}$ receptors (C) in the frontal cortex (FC), nucleus accumbens (NAC) and Ventral tegmental area (VTA). Data are plotted as mean $\pm S D(n=7)$. ${ }^{*}$ Significantly different from control

in the corners versus time spent in the center zone in OF test as well as increased immobility time of treated groups when compared to normal control ones (Fig. 1). Surprisingly, these findings are in contrast with other studies that revealed anti-anxiety potential of HCA containing herbal products [28-30].

Patients suffering from schizophrenia experience cognitive dysfunction, social withdrawal, and diminished emotional expressiveness, which manifests as lack of motivation, depression, and anxiety [31, 32]. In threechamber social interaction test, GC extract treatment at both doses lead to both reduced sociability and social novelty (Fig. 2). The present study group could be the first to assess such a behavioral alteration of HCA containing herbal products. This finding is of crucial importance as a significant side effect of the chronic use of GC extract 
when trying to lose weight. Cloninger's psychobiological model of personality proposes that dopaminergic system functioning influences personality traits such as greater tendency to novel stimuli, sociability, and impulsiveness [32-35]. Furthermore, the consequence of Garcinia cambogia extract administration on dopamine and HVA content and $D 2$ receptor expression was investigated in this study. The reduced sociability and social novelty activity may be the outcome of declined dopamine turnover (manifested by the increased DA content in the VTA and reduced HVA levels in NAc as shown in Fig. 3) as well as the increased expression of D2 receptor especially in the VTA. Bariselli et al. showed that chemo-genetic inhibition of DA neurons of the VTA attenuates exploration toward nonfamiliar conspecifics and interferes with the reinforcing properties of nonfamiliar conspecific interaction in mice [36]. In addition, Shimohata et al. showed that disturbance in DA metabolism may underlie abnormal change in sociability behaviors in Ts1Cje mice model [37]. Moreover, Watson et al. showed that $D_{2}$ receptor antagonism impairs social novelty discrimination and novel object recognition in rats [38].

In conclusion, Garcinia cambogia extract, as a weight loss supplement, exhibited prominent anxiogenic effect and reduced sociability and social novelty in male mice, without impairing locomotor activity, expressing their non-involvement in CNS stimulation. GC extract showed its effect through its contribution in modulation of DA turnover and HVA levels as well as $D_{2}$ dopaminergic receptors, as evidenced by its mechanistic study. This effect is believed to be attributed to hydroxycitric acid present in GC. However, detailed studies need to be carried out on large scale at preclinical and/or clinical level to obtain the results with high statistical significance or high level of confidence. The use of Garcinia cambogia as herbal weight loss supplement could have potential effect but would be accompanied with other behavioral and social side effects.

\section{Declarations}

Conflict of interest The authors declare that they no conflict of interest.

Open Access This article is licensed under a Creative Commons Attribution 4.0 International License, which permits use, sharing, adaptation, distribution and reproduction in any medium or format, as long as you give appropriate credit to the original author(s) and the source, provide a link to the Creative Commons licence, and indicate if changes were made. The images or other third party material in this article are included in the article's Creative Commons licence, unless indicated otherwise in a credit line to the material. If material is not included in the article's Creative Commons licence and your intended use is not permitted by statutory regulation or exceeds the permitted use, you will need to obtain permission directly from the copyright holder. To view a copy of this licence, visit http://creativecommons. org/licenses/by/4.0/.

\section{References}

1. WHO. (2021a, June 9). Obesity and overweight. Fact Sheets. https://www.who.int/news-room/fact-sheets/detail/obesityand-overweight.

2. WHO. (2021b, June 9). Obesity and overweight. Fact Sheets. https://www.who.int/news-room/fact-sheets/detail/obesityand-overweight

3. WHO. (2021c, April 13). Noncommunicable diseases. Fact Sheets. https://www.who.int/news-room/fact-sheets/detail/ noncommunicable-diseases.

4. Chuah LO, Ho WY, Beh BK, Yeap SK (2013) Updates on antiobesity effect of Garcinia origin (-)-HCA. Evidence-Based Complement Alternat Med. https://doi.org/10.1155/2013/751658

5. Semwal RB, Semwal DK, Vermaak I, Viljoen A (2015) A comprehensive scientific overview of Garcinia cambogia. Fitoterapia. https://doi.org/10.1016/j.fitote.2015.02.012

6. Roy S, Rink C, Khanna S, Phillips C, Bagchi D, Bagchi M, Sen CK (2003) Body weight and abdominal fat gene expression profile in response to a novel hydroxycitric acid-based dietary supplement. Gene Exp. https://doi.org/10.3727/0000000037 83992289

7. Altiner A, Ateş A, Gursel FE, Bilal T (2012) Effect of the antiobesity agent Garcinia cambogia extract on serum lipoprotein (a), apolipoproteins $\mathrm{a} 1$ and $\mathrm{b}$, and total cholesterol levels in female rats fed atherogenic diet. J Anim Plant Sci 22:872-877

8. Klein-Júnior L, Antunes M, Linden R, Vasques C (2010) Quantification of (-) hydroxycitric acid in marketed extracts of Garcinia cambogia by high performance liquid chromatography. Lat Am J Pharm 29:835-838

9. Voigt J-P, Fink H (2015) Serotonin controlling feeding and satiety. Behav Brain Res. https://doi.org/10.1016/j.bbr.2014.08.065

10. Heymsfield SB, Allison DB, Vasselli JR, Pietrobelli A, Greenfield D, Nunez C (1998) Garcinia cambogia (Hydroxycitric Acid) as a potential antiobesity agent. JAMA. https://doi.org/10.1001/ jama.280.18.1596

11. Bostock E, Kirkby K, Garry M, Taylor B, Hawrelak JA (2018) Mania associated with herbal medicines, other than cannabis: a systematic review and quality assessment of case reports. Front Psychiatry. https://doi.org/10.3389/fpsyt.2018.00280

12. Cotovio G, Oliveira-Maia AJ (2016) Hypomania induced by a Garcinia cambogia supplement. Aust N Z J Psychiatry 51:641-642

13. Hendrickson BP, Shaikh N, Occhiogrosso M, Penzner JB (2016) Mania induced by Garcinia cambogia. Primary Care Companion CNS Disorders. https://doi.org/10.4088/PCC.15101890

14. Lopez AM, Kornegay J, Hendrickson RG (2014) Serotonin toxicity associated with Garcinia cambogia over-the-counter supplement. J Med Toxicol. https://doi.org/10.1007/s13181-014-0390-7

15. Nguyen DC, Timmer TK, Davison BC, McGrane IR (2019) Possible Garcinia cambogia -induced mania with psychosis: a case report. J Pharm Pract. https://doi.org/10.1177/0897190017734728

16. Liao C-H, Sang S, Liang Y-C, Ho C-T, Lin J-K (2004) Suppression of inducible nitric oxide synthase and cyclooxygenase- 2 in downregulating nuclear factor-kappa B pathway by Garcinol. Mol Carcinog. https://doi.org/10.1002/mc.20050

17. Mazumder MK, Bhattacharjee N, Borah A (2016) Garcinol prevents hyperhomocysteinemia and enhances bioavailability of L-DOPA by inhibiting catechol-O-methyltransferase: an 
in silico approach. Med Chem Res. https://doi.org/10.1007/ s00044-015-1472-z

18. Arias-Carrión O, Stamelou M, Murillo-Rodríguez E, MenéndezGonzález M, Pöppel E (2010) Dopaminergic reward system: a short integrative review. Int Arch Med. https://doi.org/10.1186/ 1755-7682-3-24

19. Picchioni MM, Murray RM (2007) Schizophrenia. BMJ. https:// doi.org/10.1136/bmj.39227.616447.BE

20. Phillips AG, Vacca G, Ahn S (2008) A top-down perspective on dopamine, motivation and memory. Pharmacol Biochem Behav. https://doi.org/10.1016/j.pbb.2007.10.014

21. Paylor R, Spencer C, Yuvapaylor L, Piekedahl S (2006) The use of behavioral test batteries, II: effect of test interval. Physiol Behav. https://doi.org/10.1016/j.physbeh.2005.09.002

22. Chiroma SM, Mohd Moklas MA, Mat Taib CN, Baharuldin MTH, Amon Z (2018) d-galactose and aluminium chloride induced rat model with cognitive impairments. Biomed Pharmacother. https://doi.org/10.1016/j.biopha.2018.04.152

23. Ibrahim MK, Kamal M, Tikamdas R, Nouh RA, Tian J, Sayed M (2020) Effects of chronic caffeine administration on behavioral and molecular adaptations to sensory contact model induced stress in adolescent male mice. Behav Genet. https://doi.org/10. 1007/s10519-020-10003-1

24. Seibenhener ML, Wooten MC (2015) Use of the open field maze to measure locomotor and anxiety-like behavior in mice. J Vis Exp. https://doi.org/10.3791/52434

25. Wang C, He L, Yan M, Zheng G, Liu X (2014) Effects of polyprenols from pine needles of Pinus massoniana on ameliorating cognitive impairment in a d-galactose-induced mouse model. Age. https://doi.org/10.1007/s11357-014-9676-6

26. Shaif NA, Jang D, Cho D, Kim S, Seo DB, Shim I (2018) The antidepressant-like effect of lactate in an animal model of menopausal depression. Biomedicines. https://doi.org/10.3390/biomedicin es6040108

27. Kessler RC, Berglund P, Demler O, Jin R, Koretz D, Merikangas KR, Rush AJ, Walters EE, Wang PS (2003) The epidemiology of major depressive disorder. JAMA. https://doi.org/10.1001/jama.289.23. 3095

28. Dhamija I, Parle M, Kumar S (2017) Antidepressant and anxiolytic effects of Garcinia indica fruit rind via monoaminergic pathway. 3 Biotech. https://doi.org/10.1007/s13205-017-0766-x

29. Ohia SE, Awe SO, LeDay AM, Opere CA, Bagchi D (2001) Effect of hydroxycitric acid on serotonin release from isolated rat brain cortex. Res Commun Mol Pathol Pharmacol 109(3-4):210-216
30. Ohia SE, Opere CA, LeDay AM, Bagchi M, Bagchi D, Stohs SJ (2002) Safety and mechanism of appetite suppression by a novel hydroxycitric acid extract (HCA-SX). Mol Cell Biochem. https://doi.org/10.1023/A:1019911205672

31. Correll CU, Schooler NR (2020) Negative symptoms in schizophrenia: a review and clinical guide for recognition, assessment, and treatment. Neuropsychiatr Dis Treat. https://doi.org/10. 2147/NDT.S225643

32. McCutcheon RA, Reis Marques T, Howes OD (2020) Schizophrenia-an overview. JAMA Psychiat. https://doi.org/10.1001/ jamapsychiatry.2019.3360

33. Cloninger C (1999) Personality and psychopathology. American Psychiatric Press, New York

34. Cloninger CR (1993) A psychobiological model of temperament and character. Arch Gen Psychiatry. https://doi.org/10.1001/ archpsyc.1993.01820240059008

35. Cloninger CR, Svrakic NM, Svrakic DM (1997) Role of personality self-organization in development of mental order and disorder. Dev Psychopathol. https://doi.org/10.1017/S09545794970014 $8 \mathrm{X}$

36. Bariselli $S$, Hörnberg $H$, Prévost-Solié $C$, Musardo $S$, HatstattBurklé L, Scheiffele P, Bellone C (2018) Role of VTA dopamine neurons and neuroligin 3 in sociability traits related to nonfamiliar conspecific interaction. Nat Commun. https://doi.org/10. 1038/s41467-018-05382-3

37. Shimohata A, Ishihara $K$, Hattori $S$, Miyamoto $H$, Morishita $H$, Ornthanalai G, Raveau M, Ebrahim AS, Amano K, Yamada K, Sago H, Akiba S, Mataga N, Murphy NP, Miyakawa T, Yamakawa K (2017) Ts1Cje Down syndrome model mice exhibit environmental stimuli-triggered locomotor hyperactivity and sociability concurrent with increased flux through central dopamine and serotonin metabolism. Exp Neurol. https://doi.org/10.1016/j. expneurol.2017.03.009

38. Watson DJ, Loiseau F, Ingallinesi M, Millan MJ, Marsden CA, Fone KC (2012) Selective blockade of dopamine D3 receptors enhances while D2 receptor antagonism impairs social novelty discrimination and novel object recognition in rats: a key role for the prefrontal cortex. Neuropsychopharmacology. https:// doi.org/10.1038/npp.2011.254

Publisher's Note Springer Nature remains neutral with regard to jurisdictional claims in published maps and institutional affiliations. 